\title{
Connecting Social Capital by Social Media
}

\author{
Halvdan Haugsbakken \\ Department of Sociology and Political Science, \\ Norwegian University of Science and Technology, Trondheim, Norway \\ Halvdan. Haugsbakken@svt.ntnu.no
}

\begin{abstract}
Established sociological research on social networks and social capital has argued that large quantities of connections can represent access to resources. This claim has been challenged, due to the advent of social network sites. Researchers have little insights on how social actors use social network sites to organise particular web mediated social practices, besides for knowing they are employed for socialisation. There is also little research on how social actors use and connect to different social media applications and apply the resource embedded in them. This paper addresses that matter. It introduces a user perspective on how a group of social actors use a variety of social media application as resources, to carry out web mediated social practices. To empirically analyse this, the paper shows how a sample of Norwegian high school students use different types of social media applications for this purpose.
\end{abstract}

Keywords: social capital, social media, youth, resources, Norway.

\section{Introduction}

Norwegians spend significant time on different social media platforms, like blogs, content communities, and Social Network Sites (SNSs). Norwegians are digitally literate, considering that only 5 million reside in the country. The Norwegian online press has estimated that 2.8 million Norwegians are connected to Facebook [1]. National surveys suggest that approximately 410.000 check their Twitter account each week [2], while 641.000 have created a user profile on Linkedin [3]. 300.000 are claimed having tried Google+ [4]. Many are users of tablets too, approximately 700.000 [5]. Although these are estimations made by the online news press, we can assume that Norwegians are connected to multiple web services, forming is a systematic user pattern. The estimations also suggest that Norwegians have access to a large pool of resources.

The interesting research question remaining addressing, however, is to what extent such numbers are believable. Such assessments can fall short. They give little insights on particular uses of SNSS and how they are organised. Empirical research on Norwegians' use of SNSs, for example, suggests this [6-9]. The research community still lacks empirical knowledge, on what Jenkins calls the "participative culture" [10] of SNSs and social capital. Researchers are even now investigating users' connecting strategies, motivation for use, user characteristics and user topologies, privacy matters, online social identity management, and organisations' use [11]. Such topics dominate due to that quantitative research lead the way in forming current research [12]. 
There are other issues too. Current studies often address use of one social network site, not several and how they are combined. They are also U.S. context-based and focus on few demographic variables, chiefly, American university students $[11,12]$.

Consequently, researchers still have little accurate research knowledge on how social actors make use and extract capital form the vast resources found in social media platforms, moreover, how they transform and utilize them as part of social practices belonging to larger socio-cultural contexts. Furthermore, we need to know more on what role the combination of off-line and on-line ties play in the complex coordination of social life.

This paper considers that matter. The paper examines three distinct social practices, which are neatly embedded and transpire from social actors' use of social media software. The paper examines how a cohort of Norwegian high school students use Facebook as a tool to (1) coordinate formal schoolwork, (2) as a mean to organise drivers for weekend partying, and (3) how YouTube tutorials can work as a learning resource to play music instruments and online gaming. Substantiating this argument, a look at the article's content pertains. The paper establishes an explorative user perspective on how a data sample of Norwegian high school students use different types of social media applications, understood as a form of social capital. First, relevant research on social network and social capital are accounted for. Second, choice of methods and data sample is outlined. Third, the study's results and findings are analysed, before the last part provides a preliminary conclusion.

\section{Theoretical Inspiration and Research Horizon}

The advent of Web 2.0 [13] services has involved the introduction of technical definitions. Boyd and Ellison define SNS as a "web-based services that allow individuals to construct a public or semi-public profile within a bounded system, articulate a list of other user with whom they share a connection, and view and traverse their list of connections and those made by others within the system" [14]. This definition involves that Facebook is a SNS, while "old" pages, like blogs are not [15]. Kaplan \& Haenlein have defined social media as a "group of Internet-based applications that build on the ideological and technological foundations of Web 2.0, and that allow the creation and exchange of User Generated Content" [16]. They suggest that social media consists of six types; (1) collaborative projects, e.g. Wikipedia, (2) blog, (3) content communities, e.g. YouTube (4) SNS, e.g. Facebook, (5) virtual game worlds, e.g. World of Warcraft, (6) and virtual social worlds, e.g. Second Life [16].

These technical definitions touch upon sociological concepts of the social networks, ties, and social capital, but do not accentuate the social side of technologies. The advent of SNSs has reintroduced new research interest in social network analysis and social capital. Sociological work has been associated with Bourdieu [17],Coleman [18], Burt [19, 20], and Lin [21, 22]. Sociological research has argued that social capital is a resource found in social ties. These potential resources are assumed to be integrated in the social structures of social networks. Such resources can be emotional support and diffusion of ideas. Sociologists claim that social capital can possess the capacity of fostering cooperation between individuals or groups. It shares similar capacities to other forms of capital we normally associate that can provide 
economic growth, like financial capital. This means that social capital can be mobilised, in order to carry out social practices in social situations. This means that the value of ties and resources embedded in social media platforms can be employed by humans to carry out social practices. The question of a task's coordination would influence the success of how well a social practice is executed.

Early sociological work criticized the limited understanding of the social dynamics of ties in social networks. Granovetter's [23] "the strength of weak ties", claimed that the qualities in close ties between social actors were undertheorised. Granovetter suggested that remote ties played a more significant role in who social actors choose to connecting with. Connecting strategies become a central part of social capital, having consequences for how communities are formed and perceived too. Putnam [24] has suggested two forms of social capital, bonding and bridging. Bonding refers to resources coming from close relationships, while bridging are benefits which might come from casual or remote ties. Lin [21] argued for the theory of "instrumental action", suggesting that actors who invest in weak ties are likely to be benefiters. These approaches, however, theoretically assumes a resources are scarce and mutual recognition of action or tie. They also assume a type of game-theory approach, where social actors rationally compete and calculate their actions in social situations characterised by lack of resources.

In the digital age, it is all reversed. Information, resources, and ties, are abundant. This implies that consumption of digital devices and data sharing can have positive impact on social capital. The reoccurring analytical conundrum with current research, is that we have little knowledge on how the actual SNS use, practices, and patterns [25] transpire and are applied to coordinate tasks in social situations. Researchers are still bound to question the legitimacy of connections [26, 27]. Caers et.al argue that "our understanding is still quite fragmented and may lack nuances that characterize different settings, countries, and demographic variables" [11]. I argue that current research is too often concerned with understanding social capital to a limited number of SNSs. We need to expand our understanding beyond SNS and include "social media" more broadly, implying more detailed analysis on how different Web 2.0 applications connect with each other. Moreover, how social actors' interaction with user-generated content, can be seen as resources and a mean for cooperation and coordination.

\section{Methods and Data Sample}

The study's research design is based on a social scientific research methodology. The study applied an explorative approach. 26 students were interviewed by use of qualitative in-depth interviews, 17 boys and 9 girls. There were no gender criteria for choice of informants. Informants were recruited from two classes at a high school in Trondheim, Norway. Vocational study programs in the Norwegian education system, for example, tend to be gendered. It is not uncommon to find classes in construction classes to only consist of males. The data sample is a reflection of its social setting. 12 interviews were carried out, 10 in groups, consisting of pairs to four students. Two interviews were completed individually, meaning a face-to-face conversation between researcher and student. The interviews lasted from 20 minutes to one hour. All 
interviews were semi-structured, but followed a guide with predefined questions. The interviews explored the students' user experiences. Concrete themes were investigated. After interviewing, the interviews were transcribed and patterns were attempted established. To complete this analytical goal, the sociological data analysis technique constant comparative method [28, 29] was used. The students' answers were coded and grouped into specific themes.

Table 1. The data sample employed in study, showing background of informants

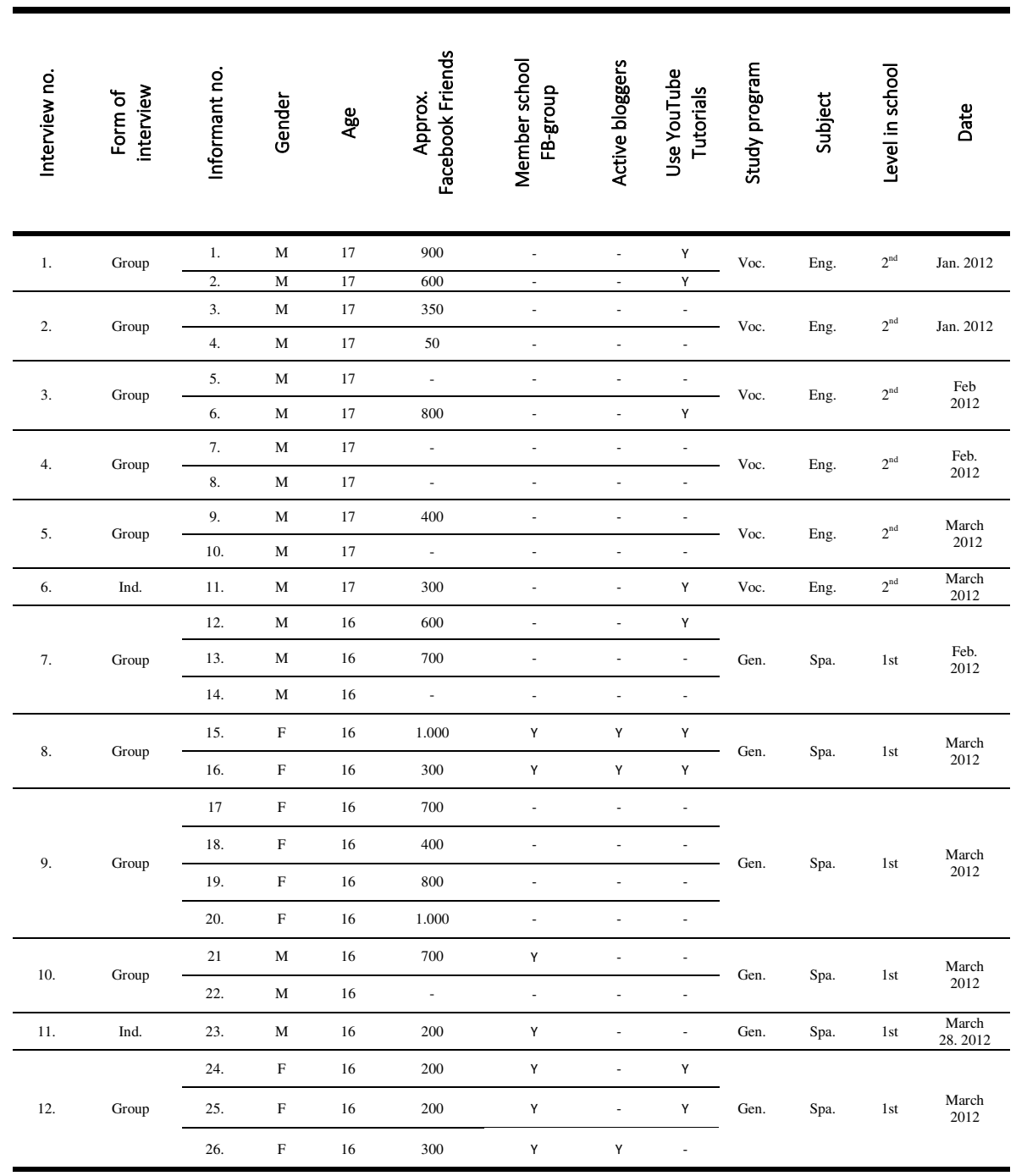




\section{Data Analysis}

The data analysis is intended at showing the study's findings. The following data analysis is divided into two parts. The first part considers recent tendencies among youth's use of social media applications. The second part will analyse three distinct web mediated social practices. The latter examines how students use Facebook as a tool to (1) coordinate formal schoolwork, (2) as a mean to organise drivers for weekend partying, and (3) how YouTube tutorials can work as a learning resource to play music instruments and to learn gaming.

\subsection{Part I: The Changing Web Landscape of Social Media}

On a general level, the data shows that the students used social media for online socialisation activities and informal learning. They were "thick consumers" of social media. They used social media applications every day, either for passive or active purposes. They had all access to cell or smart phones or portable computers, either at their school or at home. Consumption of mediated computer practises played a crucial role in what it means to be teenager. Digitally "ubiquitous" is a suitable description. Online engagement was commonplace. The projected norm was that a teenager could be accessible 24/7, although one finds variations. This is often presented along a scale of being "always in there", which applied especially to Facebook, to just knowing "what is going on". The dualism between the "on-line" vs. off-line is blurred, but the students had a situational awareness on when it applied. It was often projected that they had an on-going cognitive scripted conversation with someone all the time. The majority of the informants communicated that they did not have a zealous relationship to social media. In other words, the data does not debunk previous research knowledge on youth mediated culture on this level.

The students were digitally informed citizens. They had considerable user experience. All had some previous user experience, prior to interviewing. This included five to six years of consumption of digital devices. Sometimes it was longer than that. They became consumers of desktops or portable computers and cells the age 13 or 14 . The first introduction to the online world came often as the result of available resource facilitated by a close tie. A family laptop or desktop, for example, would serve as access to the virtual world. Others would gain more systematic access to the Internet by part-time working. Private wealth was a factor that decided if they had easy access to consumption of social media, than for example that this was enabled by prior schooling. Several informants, for example, had years of user experience before becoming Facebook users. The first introduction started with the Norwegian online community, Nettby, ${ }^{1}$ before they registered as Facebook users in 2007/08, and later became part of the Twitter community in 2012.

The students were predominantly portrayed a consumers than prosumers user profile. They conveyed themselves as "passive web 1.0" users than active "Web 2.0" users. They had a "read-only" than "read-and-write" approach and lurked publically more than being active content-producers. The students were conscious that an

\footnotetext{
${ }^{1}$ See: http://en.wikipedia.org/wiki/Nettby for more background information.
} 
ambiguous audience could potentially exploit them. Content creation was associated with risk, although many did not mind that their names could be googled or were searchable on other search engines. Privacy was a major concern and online interacting was characterised by strong conformity and self-censorship. This is reflected in how the engaged online, which was restricted to private digital rooms. They engaged online in exclusive rooms where trust in ties is exercised. Many still used e-mail and SMS as a way of communicating, in addition to reading online newspapers on a daily bases. The voice-over-IP service Skype was also popular. Use of chatting software was one of the main ways of communicating with ties, which often happened on Facebook. Some referred to Facebook's integrated chat software as the new "SMS". Few students were content creators. Only four of 26 students had regularly published web contents. Three girls had created blogs and blogged regularly. One male student had published a YouTube video. Even the students who published online content, exercised rigours ideas on what they could publish online.

The students navigated between four types of social media applications, where Facebook played a centring, connecting, and organising role on top of the other web 2.0 applications. Students divided their online time between; (1) SNSs, (2) video-sharing communities, (3) online gaming and (4) blogs. This division follows strong gendered ideas and values. They are almost sectorial, where blogging and gaming represented a digital "off-limit space" to the opposite sex. SNSs and video-sharing represented a more "gender-neutral" space.

Blogging was popular among the female students, but controversial among the males. Some male students expressed their prompt annoyance. The males claimed that they did not read blogs, as it was a "girl thing". "Blogs is for girls", as one informant expressed it. If they read one, they only admitted watching pictures. The gendered youth divide was related to the particular Norwegian mediated practice of "rosalboggere", or "pinkbloggers", translated into English. Unclear on its cultural nature, it can be understood as a form of an individualised young adult consumer culture lifestyle, dedicated to the experimentation on feminine practices and online social identities. Youth blog about their everyday life, emotions, love-life, social issues, and endorse commercial products, acting as role model for young adults. This online category has risen to be a form of symbolic representation of a successful teen, although being heavily criticized for monetising and uncritical personal branding. Pinkbloggers are also controversial public figures or celebrities. Some have their own TV-show, like Sophie Elise Isachsen, where she essentially talks about her everyday life. ${ }^{2}$ The pink blogging practice is connected to the site blogg.no, which many of the female informants read on a daily bases. Female students approached blogging predominantly from a consumer approach.

Online gaming was a youth male domain. Some female students had gamed, but briefly. Males explained that they had gamed for years, portraying it as an important leisure practice. Gaming could last for hours. It was a weekend hobby. Friends congregated and played Call of Duty or Counter Strike. Some males were reluctant to speak about the numbers of hours they spent in front of a PC or video game machine. Many male students stated they had started cutting down on gaming. It was portrayed as "dull"; and, if, a male student still spent hours on gaming, he was somehow considered as "non-adult".

${ }^{2}$ Sophie Elise Isachsen's blog: http: / / sophieelise.blogg . no 
YouTube was a favourite one among both sexes, portrayed as a "neutral" space. YouTube was used for different purposes; downloading music, just watching small video clips, and studying YouTube tutorials. These were the most common user practices. Many students used YouTube tutorials to learn how to play music instruments or how to play an online video game.

Facebook was the most popular social media application. All informants had a user profile. It was common having among 300 online friends, while some had 1.000 connections. Many had been users since 2008. The students reported contradictory habits. On the one hand side, they were connected everyday as "online-lookers", but on the other hand, stated a type of attitude of not being the one who contributed to online interaction and sharing, forming a "user paradox self-control". They exercised conformity, reflecting a high degree of editorial control and self-critical online stagemanaging of their online self. This appeared being the outcome of an established online socialisation experience. Many years of use reflected a reoccurring pattern. When they first started using Facebook, they engaged deeply, but later took a shallow position. This appeared creating normative strategies for online engagement, rendered in critical beliefs for ideal use. This was reflected in distinct unwritten ideas for interacting on Facebook, forming as discourse for "proper Facebook use and etiquette". I will give examples.

First, the students now classified Facebook as culturally "dull". They were disappointed with Facebook, because "nothing happen there". Few students admitted posting or contributing to a public online dialogue. Second, user stories also showed another reoccurring pattern. Many said that they first wrote status updates, but stopped with it. Later they liked, but also stopped doing that, to just watch pictures. Third, this user pattern did not involve full stop in communicating. They communicated in closed web spaces, to Facebook's chat channels, where they interacted with strong connections. Fourth, we also find informants who stated that they had stop adding ties to their online Facebook network. Facebook networking was not a fashion anymore. It was rare, and they had somehow finished "networked", meeting a social "saturation point". It was more uncommon to come across students who recently had become Facebook users. When getting a friend request, they would often treat it with scepticism and run a "background check", to find out who it was and how they were related, implying a strong degree of social selection. Fifth, there were reported cases that students questioned the value of having large online social networks. Some had for example started down-scaling or "unfriended" their ties. One female student told that she had "de-networked" her Facebook network from 1.000 to 300 connections. Sixth, an odd attitude conveyed in the interviews was a sort of "teenage anxiety" mind-set, which acted as a justification for not sharing. When observing younger teenager than themselves, acting as "newcomers", they would seldom interact with them or network with them. Instead, this would acts as a justification to leave Facebook, and head toward Twitter, which were their new online playground.

\subsection{Part II: Three Social Web Mediated Practices Connecting Social Capital}

Based on review data, one can observe a user pattern showing influence of social networks and social capital. Students experience less positive value of networking. Large networks make little sense possessing, as they realise that they interact in with a 
limited number of ties. One identifies a "devaluating" in the quality of ties. Large access to online resources could have negative influence on social capital. Online socialisation can be argued of not providing access to particular interesting resources. On the other hand, when examining particular use of social media practices, one can potentially identify how social actors draw upon ties or resources in their social networks, which can suggest positive influence and use social capital. In order for this to work, requires that social actors execute social actions and coordinate task. The below sections will analyse three practices.

\section{Practice 1: Trading and sharing formal school work}

The first particular use of social media connects to how students use Facebook as a coordination site to organise schoolwork. Seven students, five female and two males, were members of school related Facebook groups reported, all attending general or academics studies, a study program preparing students for university studies. These were self-organised and moderated by the students themselves. Data suggests that there were two to five closed groups, while three were class-based. Students emphasized that they were useful and used them continuously. The Facebook groups acted either as a type of "class bulletin board" or "discussion forums", where the latter use was often related to assignments. They often shared information on practicalities. We find variations in what types of digital items were shared; information on what they have in homework for next class, which pages they are supposed to read for a particular lesson, for example. Cram sheets were popular items too, acting as a valuable and requested online resource. Sharing, however, was seldom based on a motivation to participate in a reflective process with the aim of turning data to knowledge on a distinct topic or subject. The Facebook groups are bulletin boards, a sort of a "student answering service", where communication is done individually with the expectation of an answer. There is a low threshold for sharing and anybody can post anything without having the risk of being bullied, for example. The groups acted as a supplement to the regular reminders students do face-to-face. The students' sharing reminds much of the old "work plan", a sheet, which teachers in the lower levels of the education system handed out to students at the beginning of each week. This student explains:

I-21: "And, then we have the class, we have an own Facebook group. When we have tests, for example, we can share cram sheets. If there is not someone who has done their homework, then we can share, so we can talk to each other, what is our homework for the next day, what is the work for the next week. In that sense, it is very convenient."

Data analysis also shows innovative ways in which social media applications are combined, with the intention collaboration. Female students in academic studies established temporary Facebook group, which were part of a larger cross-disciplinary project. In the groups, they commented on links and discussed the project's purpose, thus relating social web to a goal driven learning. Facebook groups acted as discussion forums, a type of digital "notebook", while they finalised their work in Google Docs. One of the female students explains. 
I-15: We had a group project, "2050 Trøndelag”, on how Trøndelag is going to be in the year 2050. There we had a Facebook group, where we discussed what we were writing, what we should put in our project, what was relevant to have, and things like that.

R: Who was most active in that group? Was it you?

I-16: No, it was not a big group. All contributed. We were five students, but the fifth did not do much. We were contributing all together. And we used Google Docs.

\section{Practice 2: Organising drivers by faceworking}

The second practice connects to how social media is integrated part of a much debated issue in the Norwegian public sphere, illegal taxicab operation. Taking an official taxi under regular fairs is expensive, a factor which has led to that young adults look for inexpensive and unregulated alternatives to get home after partying on weekends. Facebook groups and Facebook ties have risen to work as a type of "unofficial" unregulated "call centre", where vital contact information on potential drivers and fairs is shared. It is a small-scale dubious re-invention of ties in social networks, where ties have a highly regarded value, possessing potential "positive" influence on social capital. Two male students explain:

I-2: $\quad$ Among my buddies, it is a lot about football.

I-1: $\quad$ A lot of football, a lot of drinking, potential parties, drivers. Very much drivers. Many updates say you can call that and that number, if you need to driver at the end of the night.

$\mathrm{R}: \quad$ Are they paid to be drivers?

I-1: Most of them charge you. This may be 200 kroner, for example, to drive someone here and there. When I get my driver licence, I'll be sure to write that I can drive an evening, for example, if I do not drink myself, though. I'm going to write that I can drive. I might perhaps charge about 50 kroners per person. I will drive them wherever they need to go.

R: Who do you drive?

I-1: Friends on Facebook, for example. I post my number, and anyone can call me.

I-2: All my friends see that it is posted there. If they are in a place and cannot get home, they just call you and ask if you can drive them home.

I-1: $\quad$ For example, and if there is anyone who know it, among those I know on Facebook, who know that I can drive, and they go to a party and I meet other many people there, who I don't know, they can disseminate to them that I drive. This might give many trips.

$\mathrm{R}: \quad$ It is a sub business that has emerged?

I-1: $\quad$ Yes. It has started to compete with the general taxi business, I think. Taking a taxi is the last resort, if you can't find a driver.

I-2: $\quad$ You call through your Facebook contact list before calling for a taxi.

I-1: $\quad$ I would rather walk home than taking a taxi.

I-2: $\quad$ If I'm at a party somewhere, and can't reach a driver, I just walk home. I'm not calling for a taxi! 
Practice 3: YouTubing to play music instrument and gaming

The third practice connects to use of "YouTube tutorials". Although YouTube has been around since 2005, the services has developed a variety of internal subgenres, which comes forwards as particular media texts. One of these are "YouTube tutorials", which constitute its own media texts. Sharing and consumption of YouTube tutorials reflects an emerging "peer-to-peer-share" social network informal learning setting. YouTube is full of tutorials. They are short videos intended for informal learning. One common theme is that someone takes on the role as a narrator, and poses as an instructor, giving a step-by-step instruction on how to do something. A tutor, with some degree of self-accumulated experience, break down the work process into separate modules or sections. The tutorials explain for example use of a software interface, how to play a song. The tutorials cover a range of topics, where an individual intends to model and disseminate knowledge or skill to anonymous learners.

Nine students explained that they used YouTube content to informal learning, which in most cases related to their hobbies. The study found that students used YouTube content to learn more about three social practices, to play a music instrument, to game, and photographing. Two female students explain how they use YouTube to learn to play instruments:

R: $\quad$ Do you use YouTube to learn?

I-15: I tried to learn from YouTube, to play guitar, but then I did not have any awesome guitar either. It was purchased in Turkey. It did not work so well for me, but I learned some chords. It is possible to use it for learning. Not that I use it so much.

R: $\quad$ Do you use to learn?

I-16: I have used it for learning.

R: $\quad$ Explain.

I-16: For piano, chords, learning stuff like that. I have always played by listening, but when I come to a point in the song, where I don't really know where I'm going, I go on YouTube. Then I see how they play, how they press the keys. So there are many "how to play video", which I have been watching.

R: $\quad$ So you use tutorials?

I-16: Yes. I have used it.

A male student explains use of YouTube to lean to game:

I-11: Most times when new games are out, all my mates meet to find out more about it. We often sit and look on YouTube to see new things. It happens when we have to learn that and that, and that's the way to do it. It's really that way we use YouTube.

R: $\quad$ So you're sitting around and talking together?

I-11: Yes, we are discussing.

R: $\quad$ It seems to very useful? It teaches you a lot?

I-11: I learn a lot from it. I think that I couldn't have been able to play, if it wasn't for YouTube.

R: $\quad$ It would have been much harder?

I-11: Yes. I'm pretty sure of that. 


\section{Conclusion}

The advent of Web 2.0 applications has involved a renewed interest in sociological research on social capital and social network. Research has mainly been interested in analysing the diffusion of ideas, values, and qualities in ties. One often established and reproduced research knowledge, is the much cited idea that "diffusion of ideas do not work" [30]. This implies that there little degree of social capital to be harvested from social media. This finding is repeated in quantitative analysis, which often miss understanding the widespread production and distribution of social practices embedded in social media. With few analytical grips, one can easily show that that there is an active, multiple production, distribution, and consumption of specific communication-based relational activities. The conundrum is that we often lack the creativity to unlock them, as they are somehow "invisible". I have only demonstrated that within a small data sample, youth engage and produce social practice in overlapping social and digital networks. Future research on social media and social capital should focus the complex social dynamics of social networks, especially the role of how task and assignments are coordinated and organised. Researchers should explore the potential production, distribution, and consumption of online resources to enhance our understanding on the relation between social capital and social media. Analysing the meaning of isolated ties will seldom suffice.

\section{References}

1. Sveinbjørnsson, S.: Så mange nordmenn er på Facebook (2013), http: / /www.digi.no/920967/saa-mange-nordmenn-er-paa-facebook (cited September 10, 2013)

2. Fossbakken, E.: Rekord for Twitter i Norge (2012), http: / /www. kampanje.com/medier/article6039802.ece (cited September 10, 2013)

3. Synlighet: Linkedin - fakta og statistikk over brukere i Norge og verden (2012), http://www. synlighet.no/linkedin/statistikk-antall-brukere/ (cited September 10, 2013)

4. Myrstad, M.: Har over 300.000 nordmenn prøvd Google+? (2012), http: / /www. mmyrstad.no/2012/01/har-over-300-000-nordmennprovd-google/ (cited September 10, 2013)

5. Fossbakken, E.: En millon brukere av tablets (2012), http: / /www. kampanje.com/medier/article6030446.ece (cited September 10, 2013)

6. Brandtzæg, P.B., Heim, J., Kaare, B.H.: Bridging and bonding in social network sites Investigating family-based capital. International Journal of Web Based Communities 6(3), 231-253 (2010)

7. Brandtzæg, P.B.: Towards a unified Media-User Typology (MUT): A meta-analysis and review of the research literature on media-user typologies. Computers in Human Behavior 26(5), 940-956 (2010)

8. Brandtzæg, P.B.: Social networking sites: Their users and social implications - A longitudinal study. Journal of Computer-Mediated Communication 17(4), 467-488 (2012) 
9. Brandtzæg, P.B., Lüders, M., Skjetne, J.H.: Too many Facebook "Friends"? Content sharing and sociability versus the need for privacy in social network sites. International Journal of Human-Computer Interaction 26(11-12), 1006-1030 (2010)

10. Jenkins, H.: Confronting the challenges of a participatory culture: Media education for the 21 th century (2006)

11. Caers, R., De Feyter, T., De Couck, M., Stough, T., Vigna, C., Du Bois, C.: Facebook: A literature review. New Media \& Society 15(6), 982-1002 (2013)

12. Brandtzæg, P.B.: Social implications of the Internet and social networking sites: a user typology approach, Oslo: Department of Media and Communication, Faculty of Humanities. University of Oslo (2012)

13. O'Reilly, T.: What Is Web 2.0? Design patterns and business models for the next generation (2005), http://oreilly.com/web2/archive/what-is-web-20.html (cited June 15, 2014)

14. Boyd, D., Ellison, N.B.: Social network sites: Definition, history and scholarship. Journal of Computer-Mediated Communication 3(1), 210-230 (2007)

15. Aalen, I.: En kort bok om sosiale medier, Fagbokforl, Bergen (2013)

16. Kaplan, A.M., Haenlein, M.: Users of the world, unite! The challenges and opportunities of Social Media. Business Horizons 53(1), 59-68 (2010)

17. Bourdieu, P.: The forms of social capital. In: Richardson, J. (ed.) Handbook of Theory And Action for the Sociology of Education, pp. 241-258. Greenwood, New York (1986)

18. Coleman, J.: Social capital in the creation of human capital. The American Journal of Sociology 94, 95-120 (1988)

19. Burt, R.S.: Structural holes: the social structure of competition. Harvard University Press, Cambridge (1992)

20. Burt, R.S.: Brokerage and closure: an introduction to social. Oxford University Press, Oxford (2005)

21. Lin, N.: Social resources and instrumental action. In: Marsden, P.V., Lin, N. (eds.) Social Structure and Network Analysis, pp. 131-145. Sage, Beverly Hills (1982)

22. Lin, N.: Building a network theory of social capital. In: Lin, N., Cook, K., Burt, R. (eds.) Social Capital: Theory and Research, Aldine de Gruyter, New York (2001)

23. Granovetter, M.S.: The Strength of Weak Ties. American Journal of Sociology 78(6), 1360-1380 (1973)

24. Putnam, R.: Bowling Alone: The Collapse and Revival of American Community. Simond and Schuster, New York (2000)

25. Ellison, N.B., Steinfield, C., Lampe, C.: Connection strategies: Social capital implications of Facebook-enabled communication practices. New Media and Society 13(6), 873-892 (2011)

26. Ahn, J.: Teenagers and social network sites: Do off-line inequalities predict their online social networks? First Monday 17(1) (2012)

27. Stefanone, M.A., Kwon, K., Lackaff, D.: The value of online friends: Networked resources via social network sites. First Monday 16 (2011)

28. Strauss, A., Corbin, J.: Basics of qualitative research: Grounded theory procedures and techniques. Sage Publications, Inc., Newbury Park (1990)

29. Strauss, A., Corbin, J.: Basics of qualitative research: Techniques and procedures for developing grounded theory. Sage Publications, Inc., Thousand Oaks (1998)

30. Wu, S., Hofman, J.M., Mason, W.A., Watts, D.J.: Who says what to whom on Twitter. In: Proceedings of the 20th International Conference on World Wide Web, Proceeding WWW 2011, Hyderabad, pp. 705-714 (2011) 